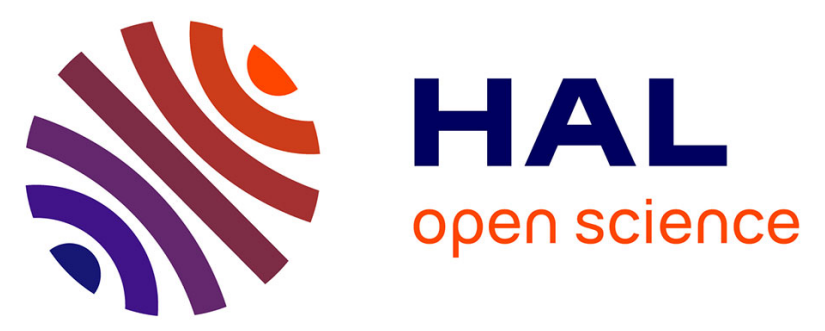

\title{
Sandwich organization of non-ionic surfactant liquid crystalline phases as induced by large inorganic K4Nb6O17 nanosheets
}

Régis Guégan, K. Sueyoshi, S. Anraku, S Yamamoto, N. Miyamoto

\section{To cite this version:}

Régis Guégan, K. Sueyoshi, S. Anraku, S Yamamoto, N. Miyamoto. Sandwich organization of nonionic surfactant liquid crystalline phases as induced by large inorganic K4Nb6O17 nanosheets. Chemical Communications, 2016, 52, pp.1594-1597. 10.1039/C5CC08948D . insu-01237520

HAL Id: insu-01237520

https://hal-insu.archives-ouvertes.fr/insu-01237520

Submitted on 15 Dec 2015

HAL is a multi-disciplinary open access archive for the deposit and dissemination of scientific research documents, whether they are published or not. The documents may come from teaching and research institutions in France or abroad, or from public or private research centers.
L'archive ouverte pluridisciplinaire HAL, est destinée au dépôt et à la diffusion de documents scientifiques de niveau recherche, publiés ou non, émanant des établissements d'enseignement et de recherche français ou étrangers, des laboratoires publics ou privés.

\section{(1) (1) $\$$}

Distributed under a Creative Commons Attribution - NonCommercial - NoDerivatives 44.0 


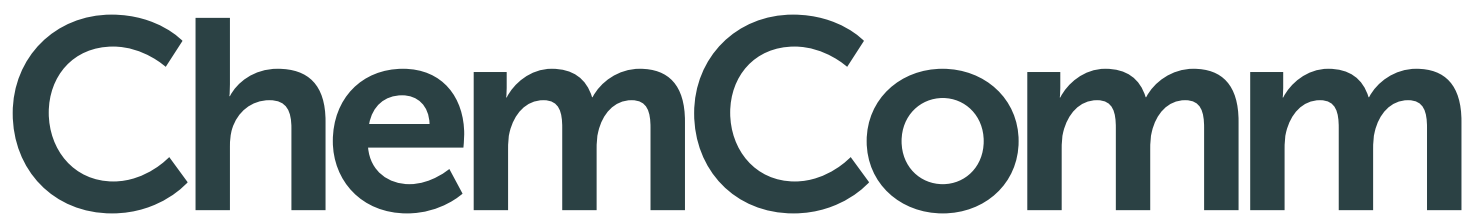

\section{Accepted Manuscript}

This article can be cited before page numbers have been issued, to do this please use: R. Guégan, K. Sueyoshi, S. Anraku, S. Yamamoto and N. Miyamoto, Chem. Commun., 2015, DOI:
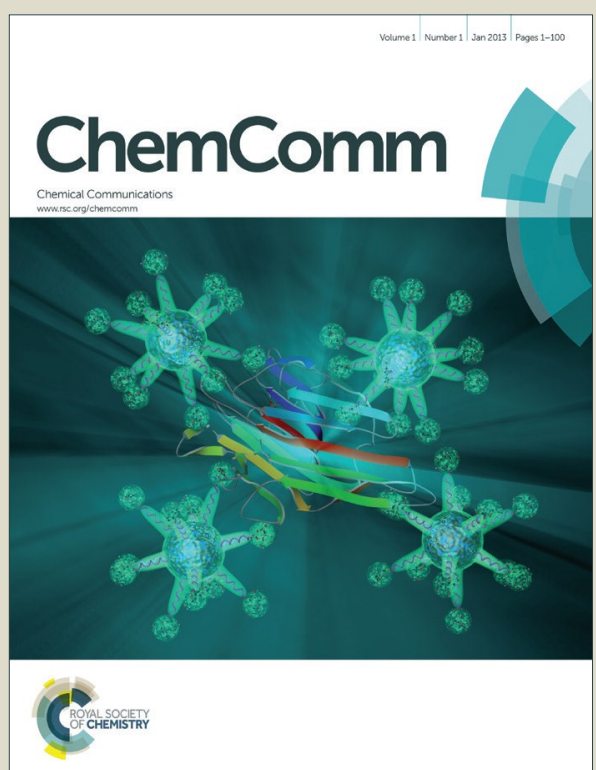

This is an Accepted Manuscript, which has been through the Royal Society of Chemistry peer review process and has been accepted for publication.

Accepted Manuscripts are published online shortly after acceptance, before technical editing, formatting and proof reading. Using this free service, authors can make their results available to the community, in citable form, before we publish the edited article. We will replace this Accepted Manuscript with the edited and formatted Advance Article as soon as it is available.

You can find more information about Accepted Manuscripts in the Information for Authors.

Please note that technical editing may introduce minor changes to the text and/or graphics, which may alter content. The journal's standard Terms \& Conditions and the Ethical guidelines still apply. In no event shall the Royal Society of Chemistry be held responsible for any errors or omissions in this Accepted Manuscript or any consequences arising from the use of any information it contains. 


\section{ChemComm}

\section{COMMUNICATION}

\section{Sandwich organization of non-ionic surfactant liquid crystalline phases as induced by large inorganic $\mathrm{K}_{4} \mathrm{Nb}_{6} \mathrm{O}_{17}$ nanosheets}

Received 00th January 20xx,

R. Guégan, ${ }^{a, b}$ K. Sueyoshi, ${ }^{b}$ S. Anraku, ${ }^{b}$ S. Yamamoto, ${ }^{b}$ and N. Miyamoto ${ }^{b}$

DOI: $10.1039 / x 0 x x 00000 x$

www.rsc.org/

While keeping its lamellar liquid crystal phase, $\mathrm{K}_{4} \mathrm{Nb}_{6} \mathrm{O}_{17}$ nanosheets were used as a template to sandwich and stabilize an alkylpoly(ethylene oxide) nonionic surfactant-water system showing a monodomain (lamella) formation within the inorganic niobate sheets that appears to not be depend to the surfactant liquid crystalline state in solution but more its concentration.

Two dimensional (2D) atomic crystals or nanosheets resulting from the exfoliation of inorganic layered materials constitute exciting nano materials with fascinating properties and diverse potential applications for constructing novel nanomaterials. ${ }^{1-3}$ The layered $\mathrm{K}_{4} \mathrm{Nb}_{6} \mathrm{O}_{17}$ niobates form extraordinary large nanoplatelets showing transparency and semi-conductivity and a lamellar liquid crystal (LC) phase that can be easily aligned at a macroscopic scale with weak magnetic or electric fields. ${ }^{4-6}$ Thus, these layered materials were commonly used as host matrixes for dye species and other organic compounds which were orientated in one direction. $^{7-9}$

Stability and microstructure of these hybrid systems result from the interplay of the attractive and repulsive forces between the colloidal exfoliated nanosheets. A small variation in the intersheet molecular force balance caused by variations in nanosheet concentration, $\mathrm{pH}$ or ionic strength variation, may induce a re-organization in the system, for instance phase separation or aggregation via an exclusion mechanism. ${ }^{10-11}$ Thus, while keeping its LC properties, the mixing between niobate nanosheets and alkylpoly(ethylene oxide) nonionic surfactants $\left(C_{n} E_{m}\right)$ that self-organize in a variety of distinct morphologies such as hexagonal, cubic, lamellar lyotropic liquid crystalline phases ${ }^{12-16}$ represents a certain challenge. ${ }^{10-12}$ Nevertheless, if the mixing leads to a homogenous solution, the resulting mixed nanostructures may couple the

\footnotetext{
a. Institut des Sciences de la Terre d'Orléans, UMR 7327 CNRS-Université d'Orléans, Orléans 45071, France. E-mail: regis.guegan@univ-orleans.fr

b. Department of Life, Environment and Materials Science, Graduate School of Fukuoka Institute of Technology, Fukuoka 811-0295, Japan

Electronic Supplementary Information (ESI) available: Experimental details and Fig. S1-S3. See DOI: 10.1039/x0xx00000x
}

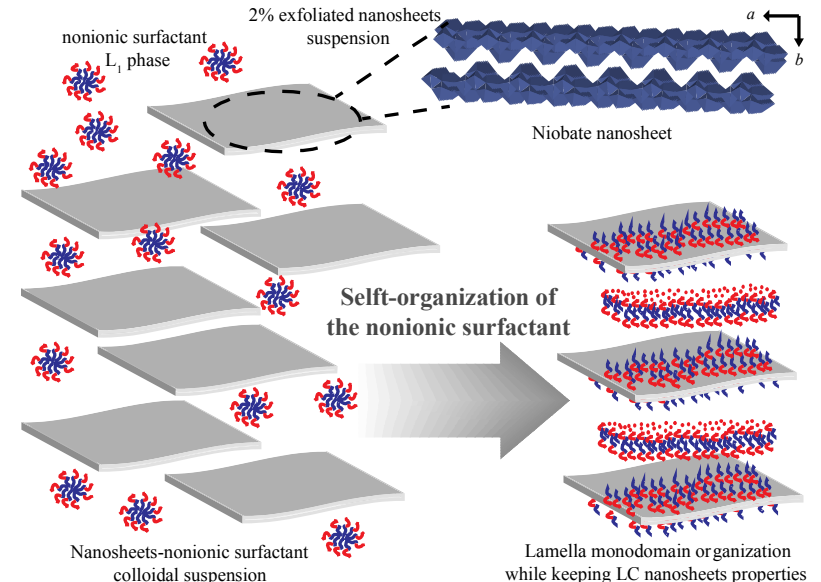

Fig. 1: Experimental protocol for the preparation of the colloidal suspensions resulting of the mixing of $\mathrm{K}_{4} \mathrm{Nb}_{6} \mathrm{O}_{17}$ niobate nanosheets lamellar phase and various liquid crystalline phases (here $L_{1}$ phase) made of $C_{12} E_{5}$ nonionic surfactants.

characteristics of both binary systems with interesting properties, such as fluid solutions with high nanosheet contents or very dilute lyotropic liquid crystalline (lamellar or else) phases with a possible enhanced stability due to the presence of nanosheets. $^{6}$

Although self assembled structure of polymeric micelles were successfully used as template for organizing flexible nanosheets in order to develop novel mesoporous materials ${ }^{17}$, the opposite preparation with the mixing of self assembled structure made of nonionic surfactant has not been studied so far. Thus, while keeping nanosheets LC phase which is rather difficult due to their tendency to aggregate once introduced an organic compound, niobate nanosheets were used as a template in order to organize and stabilize diverse liquid crystalline phases made of a non-ionic surfactant. 

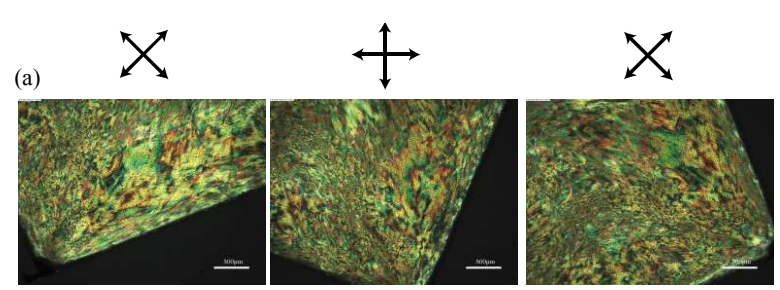

(b)
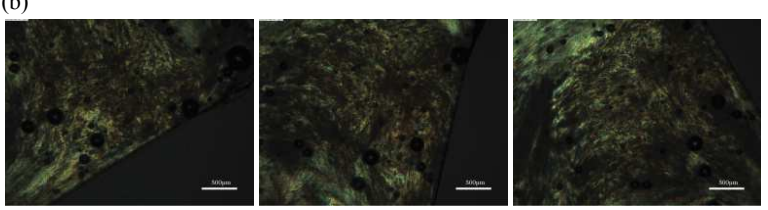

(c)
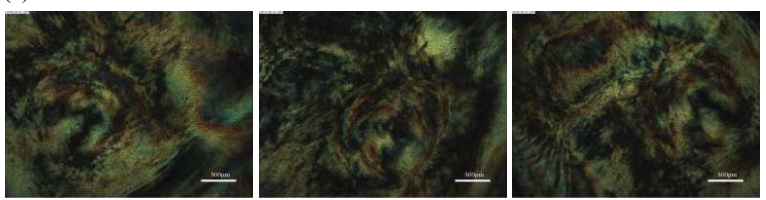

(d)
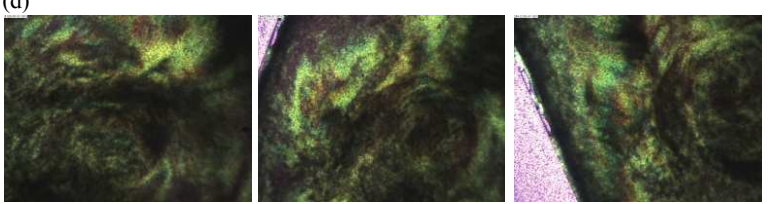

Fig. 2: Optical pictures of the samples obtained by mixing niobate nanosheets at a concentration of $20 \mathrm{~g} \mathrm{~L}^{-1}$ (a) and nonionic surfactants at a mass fraction of $w=0.15$ (b), 0.25 (c), and 0.4 (d). The whole samples display liquid crystal properties, which were confirmed under cross polarizer observations.

The experimental protocol is drawn in Fig. 1. A starting nanosheet colloidal solution was first prepared through the exfoliation of a single crystal of $\mathrm{K}_{4} \mathrm{Nb}_{6} \mathrm{O}_{17}$. The preparation of $\mathrm{K}_{4} \mathrm{Nb}_{6} \mathrm{O}_{17}$ crystal is reported in details elsewhere. ${ }^{6-9}$ $\mathrm{K}_{4} \mathrm{Nb}_{6} \mathrm{O}_{17} \cdot 3 \mathrm{H}_{2} \mathrm{O}$ crystals were delaminated into colloidal nanosheets by interaction with propyl-ammonium. Particle may be described as sheet of $\approx 1 \mathrm{~mm}$ length, $100 \mu \mathrm{m}$ width and 1.8-2 $\mathrm{nm}$ thickness and shows a density relative to water of $d_{p}=4$. The absence of any aggregation of the niobate nanosheets was confirmed by dynamic light scattering and the exfoliated nanosheets suspension display LC properties analysed through optical microscopy under cross polarizers (Fig. 2). $C_{12} E_{5}$ nonionic surfactants self-assembles in water concentration and temperature in various membrane phases (see Fig. S1-2 for both the chemical structure of the non-ionic surfactant and its phase diagram in the Supporting Information) of which thickness is estimated to reach $2.9 \mathrm{~nm} .{ }^{10}$ Samples were prepared by addition, in the niobate nanosheets suspension, of the surfactant at a mass fraction $w$ of $0.15,0.25$ and 0.4. Water was added if necessary in sufficient amount in order to get $1 \mathrm{~mL}$ volume samples. Finally, the niobate nanosheets concentration for the whole samples was set to be 20 g. $\mathrm{L}^{-1}$ (2\% in weight) leading to an accessible area of $61 \mathrm{~m}^{2} . \mathrm{g}$ 1

Conventional techniques such as confocal microscopy or light scattering for studying colloidal systems are relevant for

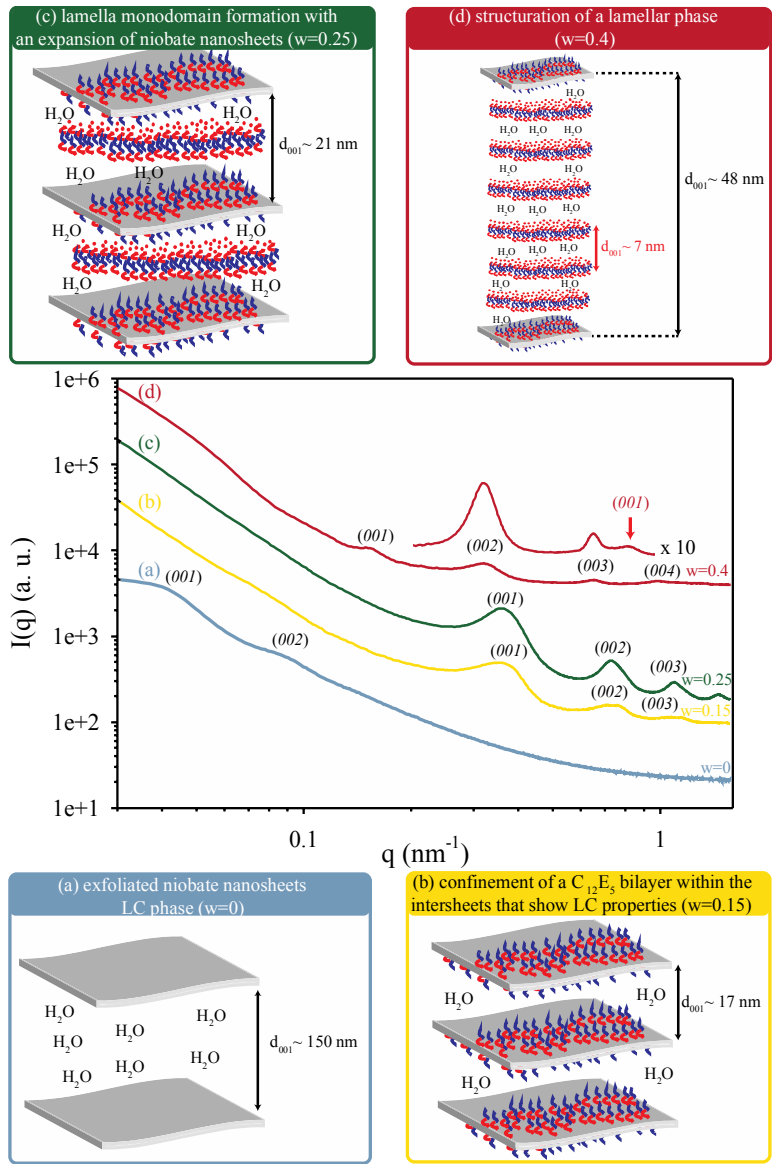

Fig. 3: Small Angle X-ray Scattering (SAXS) profiles of niobate nanosheets at a mass concentration of $20 \mathrm{~g} \mathrm{~L}^{-1}$ (in light blue labelled as (a)) with a liquid crystalline (LC) lamellar organization that can be identified by 001 reflections, and with $C_{12} E_{5}$ nonionic surfactant at a mass concentration of $w=0.15$ (in yellow labelled as (b)), $\mathrm{w}=0.25$ (in green labelled as (c)) where the nonionic surfactant shows a lamella organization, $w=0.4$ (in red labelled as (d)) displaying also a mono ordered lamellar structure that can be characterized and is highlighted with a red arrow.

the determination of aggregates size and their potential organization but cannot provide any precise information at a nanometer scale for a proper description of the nanosheets arrangement nor the non-ionic surfactant arrangement in aqueous solution. Among the techniques used for studying soft matter organization, small angle X-ray scattering (SAXS) represents a powerful and convenient tool to understand the structural changes in layered materials, since the intersheets distance between intersheets can be estimated by measuring the $d_{001}$ spacing. SAXS profile of the exfoliated niobate nanosheets at a mass concentration of $2 \%$ exhibits two order of diffraction (highlighted by the arrows in the Fig. 3), confirming the LC lamellar phase state of nanosheets suspension with a very large sheets spacing up to $150 \mathrm{~nm}$, in agreement with previous measurements on such system. ${ }^{8}$ Nonionic surfactant is properly intercalated within the intersheets space with the identification of several diffraction peaks that reflect the existence of a well ordering in the niobate sheets due to organized surfactant aggregates. In contrast to previous works where the adsorption of surfactant onto layered material surface increases the interlayer space ${ }^{10-11}$, in 
LC niobate nanosheets system, the inter-sheets collapse as it can be highlighted with the shift of the 00 l reflection to large $q$ values once surfactant at low concentration is introduced. Although surfactant aggregates geometry could not be precisely determined by any particular technique in solution, FTIR spectra (Fig. S4 in SI) give important information about the conformation of surfactant adsorbed onto nanosheets which appear to be organized in a bilayer arrangement (alltrans conformation) for the arrangement of the aggregates since nonionic surfactants are homeotropicaly adsorbed through their hydrophilic headgroups to the nanosheets surface. ${ }^{11-13}$ Although the number of surfactant molecules at low concentration is just enough to cover the whole accessible surface of the nanosheets, their 2D geometry plays as a template system to favor a semi-bilayer or bilayer organization including water layer between the sheets as it could be already mentioned in past works where such nonionic surfactant forms bilayer onto layered surface (hectorite, and montmorillonite)..$^{10-14}$

Another interesting feature concerns the surfactant phase state: it appears that liquid crystalline surfactant phase plays a minor role on the resulting surfactant aggregates onto large 2D nanosheets since samples prepared either with nonionic surfactant in a lamellar phase or in spherical micelles display similar SAXS profiles for the studied concentration range. Indeed, results obtained at the temperature of $60^{\circ} \mathrm{C}$ where the surfactant is supposed to self-assemble in a lamellar phase show comparable SAXS profiles to those at room temperature. Similar observations were obtained by keeping $w=0.15$ while playing on the studied temperature range from room temperature to $70^{\circ} \mathrm{C}$, where SAXS profiles did not show any particular strong differences (Fig. S5 in $\mathrm{SI}$ ). This underlines the importance of the geometry of the nanosheets on the aggregation process of nonionic surfactants. Indeed, once in contact to the nanosheets surface, a two-dimensional condensation occurs where the minimization of the interface energy of the adsorbed system implies a re-organization of the micelle shapes in a bilayer arrangement.

For a surfactant density above that one of the maximum that nanosheets can adsorb onto their surface (i.e. once the mass concentration is above 0.15 ), the $2 \mathrm{D}$ large nanosheets imposes a strong confinement strength, which stabilizes surfactant organization to a mono lamellar domain organization. ${ }^{18}$ Indeed, for a $\mathrm{C}_{12} \mathrm{E}_{5}$ mass concentration $w=0.4$, SAXS profile exhibits several order of diffraction attributed to the $00 /$ reflection of the intersheets layer of which $d_{001}$ spacing reaches $48 \mathrm{~nm}$, but also another $00 /$ reflection at the $q$ value of $0.83 \mathrm{~nm}^{-1}$ that does not match any order of diffraction of the layered structure of the inorganic material and is related to a $\mathrm{C}_{12} \mathrm{E}_{5}$ lamellar organization. Although, it is not expected to get any lamellar phase for such concentration and temperature, the characteristics inter-membrane $d_{001}$ spacing of a possible swollen lamellar phase can be estimated to be $d=\xi / w \sim 7 \mathrm{~nm}$ (with $w$ and $\xi$ the concentration of surfactant in the water and the thickness of a $C_{12} E_{5}$ bilayer respectively) that matches the diffraction peak at $0.83 \mathrm{~nm}^{-1}$ (highlighted in a red arrow in of which width differs from the other reflections). Thus, while keeping their LC behaviors, the confinement within the 2D large niobate nanosheets in a gap of $h \sim 50 \mathrm{~nm}$ contributes to the formation of a single ordered lamellar phase domain. Thus, niobate nanosheets drives to an ordering phase transition for $\mathrm{C}_{12} \mathrm{E}_{5}-\mathrm{H}_{2} \mathrm{O}$ system with a confinement strength of $\lambda=d$ / $h \sim 0.14$ leading to a highly ordered monodomain structure of a equilibrium lamellar phase. More interestingly, at the concentration $w=0.4$, the slit of $h \sim 50 \mathrm{~nm}$ corresponds to almost 7 times the value to that of the intermembrane $d_{001}$ spacing which can be identified in contrast to the studied lower concentration ( $w=0.25)$ where the confinement strength is more pronounced $(\lambda \sim 0.55 \mathrm{~nm})$ with nevertheless a not sufficient density of surfactant and to allow the characterization of the mono-lamellar domain (i.e. the coherent length domain is not enough to be detected here).

In summary, we demonstrate that 2D extraordinary large niobate nanosheets changes an equilibrium phase of the nonionic surfactant-water system and plays as a surface assisted nucleation system to organize in a single-domain ordered structure. Since 2D nanosheets can be easily organized at a macroscopic scale through the use of external magnetic and electric fields, the confinement of nonionic surfactant within their inter-sheets layer while keeping their particular LC properties drives to a simple physical strategy for attaining homogenous ordered phase. The importance to organize colloidal systems at short dimension is of first importance in various technological processes such as controlled microphase separation and surface segregation. Moreover, at high mass concentration of surfactant $w$, it can be expected to organize lamella domain or to create organized arrangements with dimensions comparable to the wavelength if light, wherein many opportunities exist, for example in various optical applications. Indeed, since non-ionic surfactant could be used as solvent in order to incorporate organic compounds showing functional properties such as photosensitizing dyes, the particular non-ionic surfactant lamella monodomain stabilized by niobate nanosheets represents an interesting template system for aligning organic dyes without their aggregation leading to potential applications.

The SAXS measurements were performed in SAGA-LS synchrotron facilities. The help and technical assistances of Dr. H. Setoyma were particularly appreciated. Régis Guégan was supported by the Japanese society for the promotion of science (JSPS) through a program for invited researcher (L15530). Miyamoto research group thanks the financial supports by: Network Joint Research Centre for Materials and Devices; Strategic Research Foundation Grant-Aided Project for Private University from MEXT; Canon Foundation.

\section{Notes and references}


1 F. Geng, R. Ma, A. Nakamura, K. Akatsuka, Y. Ebina, Y. Yamauchi, N. Miyamoto, Y. Tateyama, T. Sasaki, Nat Commun, 2013, 4, 1632.

2 C. Xue, M. Gao, Y. Xue, L. Zhu, L. Dai, A. Urbas, Q. Li, J. Phys. Chem. C, 2014, 118, 15332.

3 Anisotropic nanomaterials: preparation, properties, and applications, Q. Li, Springer, Heidelberg, 2015.

4 P. Davidson, J.-C. P. Gabriel, Current Opinion in Colloid \& Interface Science 2005, 9, 377.

5 J.-C. P.Gabriel, F. Camerel, B. J. Lemaire, H. Desvaux, P. Davidson, P. Batail, Nature 2001, 413, 504.

6 N. Miyamoto, T. Nakato, Advanced Materials, 2002, 14, 1267.

7 N. Miyamoto, T. Nakato, The Journal of Physical Chemistry $B$ 2004, 108, 6152.

8 N. Miyamoto, T. Nakato, Israel Journal of Chemistry, 2012, 52, 881.

9 N. Miyamoto, H. Yamamoto, R. Kaito, K. Kuroda, Chemical Communications, 2002, 2378.

10 I. Grillo, P. Levitz, T. Zemb, Eur. Phys. J. E, 2001, 5, 377.

11 J. M. Cases, F. Villieras, Langmuir, 1992, 8, 1251.

12 R. Guégan, Soft Matter, 2013, 9, 10913.

13 R. Guégan, Langmuir, 2010, 26, 19175.

14 Y. Nibu, T. Inoue, Journal of Colloid and Interface Science, 1998, 205, 305.

15 R. Strey, R. Schomacker,D. Roux, F. Nallet, U. Olsson, Journal of the Chemical Society, Faraday Transactions 1990, 86, 2253.

16 R. Guégan, Journal of Colloid and Interface Science, 2011, 358, 485.

17 B. P. Bastakoti, Y. Li, M. Imura, N. Miyamoto, T. Nakato, T. Sasaki, Y. Yamauchi, Angewandte Chemie, 2015, 127, 4296.

18 Y. Iwashita, H. Tanaka, Physical Review Letters, 2005, 95, 047801. 